\title{
Cholesterol lowering drugs and risk of age related maculopathy: prospective cohort study with cumulative exposure measurement
}

\author{
R van Leeuwen, J R Vingerling, A Hofman, P T V M de Jong, B H Ch Stricker
}

Recently, two studies have claimed that cholesterol lowering drugs, particularly statins, protect against age related maculopathy. ${ }^{2}$ The end stage of this progressive retinal disorder is the commonest cause of untreatable blindness in elderly people in Western societies, and its prevalence is expected to rise with the ageing of the population. Thus, preventing this disorder would have an enormous public health impact. ${ }^{3}$ The above mentioned studies used interview data on drug use and had a low statistical power. We therefore tested the hypothesis that cholesterol lowering drugs protect against age related maculopathy in a large cohort study with cumulative exposure measured.

\section{Participants, methods, and results}

This investigation was part of the Rotterdam study, a population based cohort study of people aged 55 years and more. After the baseline phase from 1990 to 1993, two follow up examinations were performed at mean intervals of 2 and 6.5 years. Of all the subjects at risk of age related maculopathy, $4822(83 \%)$ participated at follow up. A diagnosis of age related maculopathy was based on stereoscopic colour fundus transparencies graded according to the international was defined as the development of soft distinct drusen with pigmentary irregularities, indistinct drusen, or the end stages of atrophic or neovascular age related macular degeneration.

A register of prescriptions filled by local pharmacies provided continuous data on use of cholesterol lowering drugs. These data were available for $99 \%$ of the cohort from 1 January 1991 onwards. We used Cox proportional hazards regression analysis to calculate hazard ratios, with age in days as the time axis to ensure optimal controlling for age. Cumulative exposure to drugs was represented as a time dependent covariate and was analysed both as a dichotomous and a categorical variable. The model compared each incident case of age related maculopathy with all subjects in the cohort who were alive and free of the disorder at the age when the case of maculopathy was diagnosed.

During 26781 person years of follow up, 457 patients used cholesterol lowering drugs for one or more days, and 419 cases of incident age related maculopathy were observed. Use of cholesterol lowering drugs at any time, defined as a binary variable, was not associated with the incidence of age related maculopathy (hazard ratio 1.0 (95\% confidence interval 0.7 to 1.5)). Compared with patients who had never used cholesterol lowering drugs, cumulative exposure for less than one month, for one month to a year, or for more than a year did not have a protective effect on the risk of maculopathy (see table). Additional adjustment classification system. ${ }^{4}$ The incidence of the disorder for body mass index, hypertension, smoking, and peripheral arterial disease (ankle:arm index $<0.9$ ) did not change the association. When we performed the same analysis with progression of age related maculopathy as the outcome variable, we obtained the same results.

\section{Comment}

Exposure to cholesterol lowering drugs did not change patients' risk of age related maculopathy. In contrast with the studies that reported a protective effect, we used a prospective design and assessed drug use by means of data registered by pharmacies. This minimised potential selection and information bias, and our data provided quantitative information for each patient's cumulative exposure to drugs. This prevented misclassification of the duration of drug use. Even though the total number of participants was high, the number of subjects using cholesterol lowering drugs who developed age related maculopathy was low, possibly leading to a type II error. With a two sided $\alpha$ of 0.05 , we had a power of $80 \%$ to show a relative risk of 0.7 or lower. The fact that we did not find an association between cholesterol lowering drugs and age related maculopathy makes a protective effect of statins unlikely.

Contributors: RvL, PTVMdJ, and BHChS formulated the design of the study. RvL and JRV carried out the field work, and RvL and BHChS analysed the data. The paper was written by RvL and BHChS, and edited by JRV, AH, and PTVMdJ. AH, PTVMdJ, and $\mathrm{BHChS}$ are guarantors for the paper.

Funding: The Rotterdam study is supported by the Netherlands Organisation for Scientific Research (NWO), the Health and Development Research Council (ZON), the Netherlands Society for the Prevention of Blindness, and the Optimix Foundation.

Competing interests: None declared.

Hazard ratios of age related maculopathy (ARM) associated with the use of cholesterol lowering drugs

\begin{tabular}{|c|c|c|c|c|}
\hline $\begin{array}{l}\text { Exposure to } \\
\text { cholesterol lowering } \\
\text { drugs }\end{array}$ & $\begin{array}{l}\text { No of subjects } \\
\text { with incident } \\
\text { ARM }(n=419)\end{array}$ & $\begin{array}{l}\text { No of subjects in } \\
\text { total cohort } \\
(\mathrm{n}=\mathbf{4 8 2 2})\end{array}$ & $\begin{array}{l}\text { Crude hazard } \\
\text { ratio }(95 \% \mathrm{CI})^{*}\end{array}$ & $\begin{array}{l}\text { Adjusted hazard } \\
\text { ratio }(95 \% \mathrm{Cl}) \dagger\end{array}$ \\
\hline \multicolumn{5}{|l|}{ All drugs: } \\
\hline No exposure & 391 & 4365 & 1.0 & 1.0 \\
\hline$<1$ month & 2 & 26 & 1.1 (0.3 to 4.3$)$ & $1.2(0.3$ to 5.0$)$ \\
\hline $1-<12$ months & 8 & 136 & 1.0 (0.5 to 2.1$)$ & $1.0(0.5$ to 2.0$)$ \\
\hline$\geqslant 12$ months & 18 & 295 & $1.0(0.6$ to 1.6$)$ & $1.2(0.7$ to 1.9$)$ \\
\hline \multicolumn{5}{|l|}{ Statins: } \\
\hline No exposure $\ddagger$ & 394 & 4407 & 1.0 & 1.0 \\
\hline$<1$ month & 2 & 21 & 1.5 (0.4 to 6.1$)$ & $1.6(0.4$ to 6.5$)$ \\
\hline $1-<12$ months & 7 & 120 & 1.0 (0.5 to 2.1$)$ & 0.9 (0.4 to 2.1$)$ \\
\hline$\geqslant 12$ months & 16 & 274 & 1.0 (0.6 to 1.6$)$ & $1.1(0.7$ to 1.9$)$ \\
\hline
\end{tabular}

${ }^{*}$ Adjusted for age and sex.

†Additional adjustment for body mass index, smoking, hypertension, and peripheral arterial disease. fln this time dependent analysis, cumulative drug exposure of each case was compared with that for all other subjects in the cohort as controls, on the index date half way between the two examinations when the incident case occurred. Controls may contribute more than once. Hence, relative risks cannot be calculated with the numbers given in the table.

\section{Department of Epidemiology and Biostatistics, Centre Rotterdam PO Box 1738,3000 DR Rotterdam, the Netherlands researcher A Hofman professor \\ P T V M de Jong professor B H Ch Stricker professor \\ Department of Ophthalmology, Erasmus Medical
Centre Rotterdam, PO Box 2040, 3000 CA Rotterdam, the Netherlands \\ $\mathrm{J}$ R Vingerling Correspondence to: P T V M de Jong, \\ Netherlands Research Institute, KNAW, \\ Meibergdreef 47, \\ $1105 \mathrm{BA}$ \\ Netherlands \\ p.dejong@ \\ ioi.knaw.nl}

BMJ 2003;326:255-6 
1 Hall NF, Gale CR, Syddall H, Phillips DI, Martyn CN. Risk of macular degeneration in users of statins: cross sectional study. BMJ 2001;323:375-6

2 McCarty CA, Mukesh BN, Guymer RH, Baird PN, Taylor HR. Cholesterol-lowering medications reduce the risk of age-related maculopathy progression. Med J Aust 2001;175:340.

3 Arnold JJ, Sarks SH. Extracts from "clinical evidence": age related macular degeneration. BMJ 2000;321:741-4.

4 Bird AC, Bressler NM, Bressler SB, Chisholm IH, Coscas G, Davis MD, et al, for the International ARM Epidemiological Study Group. An international classification and grading system for age-related maculopathy and age-related macular degeneration. Surv Ophthalmol 1995;39:367-74.

5 In t' Veld BA, Ruitenberg A, Hofman A, Launer LJ, van Duijn CM, Stijnen T, et al. Nonsteroidal anti-inflammatory drugs and the risk of Alzheimer's disease. N Engl J Med 2001;345:1515-21.

(Accepted 20 August 2002)

RESEARCH POINTERS

\section{Mortality from cardiovascular disease more than 10 years after radiotherapy for breast cancer: nationwide cohort study of 90000 Swedish women}

Increased cardiovascular mortality more than 10 years after diagnosis of breast cancer is compatible with radiotherapy causing a substantial hazard

Clinical Trial Service Unit and Epidemiological Studies Unit, Radcliffe Infirmary, Oxford OX2 6HE

Sarah Darby professor

Paul McGale statistician Richard Peto codirector

Department of Medical

Epidemiology, Karolinska Institute, 17177 Stockholm, Sweden

Fredrik Granath statistician

Per Hall

professor

Department of Medicine,

Karolinska Institute Anders Ekbom professor

Correspondence to: S Darby

sarah.darby@ ctsu.ox.ac.uk

BMJ 2003;326:256-7
During radiotherapy for breast cancer there is often some irradiation of the heart and major blood vessels, which could increase cardiovascular mortality many years later. ${ }^{1-3}$ The dose of radiation to the heart is generally higher when the left rather than the right breast is affected. Therefore, indirect evidence on the magnitude of any risk is available where the tumour laterality (left or right breast) can be linked to subsequent cardiovascular mortality. ${ }^{12}$ Studies of the survivors of the atomic bombing of Japan who received single doses to the whole body of 0-4 Gy show that the cardiovascular disease risk is dose related and increases by about $14 \%$ per gray. ${ }^{4}$

\section{Participants, methods, and results}

Since 1970, the nationwide Swedish cancer registry has recorded the laterality of breast cancers but not the use of radiotherapy. Unpublished data from regional Swedish registries suggest that about $30 \%$ of women with early breast cancer during the 1970s and early ' 80 s received radiotherapy. We linked registry records (1970-96) with national mortality records. The study was approved by the ethics committee of the Karolinska Institute.

After we excluded women whose cancer was diagnosed at autopsy or outside Sweden and those with previously registered cancers (except squamous cell skin cancer), 89407 women aged 18-79 with unilateral breast cancer remained. We stratified analyses of subsequent mortality in groups of five years by calendar year of diagnosis, time since diagnosis, and age at diagnosis. Stratification by age was necessary because the proportion of left sided tumours increases with age. ${ }^{5}$ Each woman's contribution to the person years at risk ran from the date of diagnosis until her date of death, date of emigration, 100th birthday, or 1 January 1997, whichever was earliest. We used Poisson regression to calculate mortality ratios, left versus right, from the numbers of deaths and person years. Ratios greater than one indicate greater mortality in women with left sided tumours than in women with right sided tumours.

Mortality from breast cancer was identical in women with left sided or right sided tumours (table). Mortality from cardiovascular diseases was higher in women with left sided tumours. Little excess occurred in the first 10 years after diagnosis (mortality ratio $1.01 ; 95 \%$ confidence interval 0.96 to 1.07 ), but later the ratio was 1.10 ( 1.03 to $1.18 ; \mathrm{P}=0.004), 1.13$ ( 1.03 to $1.25 ; \mathrm{P}=0.01$ ) for ischaemic heart disease (half of all cardiovascular mortality), and 1.08 (0.98 to 1.18) for other cardiovascular deaths (about $30 \%$ of which

Mortality ratio for women with left sided breast cancer versus women with right sided breast cancer during and after the first 10 years from diagnosis of breast cancer among 89407 women registered during 1970-96 at the Swedish cancer registry

\begin{tabular}{|c|c|c|c|c|c|}
\hline \multirow{2}{*}{ Cause of death (ICD-9 code) } & \multirow{2}{*}{$\begin{array}{c}\text { All years } \\
\text { Mortality ratio, left } \\
\text { versus right }(95 \% \mathrm{CI})\end{array}$} & \multicolumn{2}{|r|}{$<10$ years } & \multicolumn{2}{|c|}{$\geqslant 10$ years } \\
\hline & & $\begin{array}{l}\text { No of } \\
\text { deaths }\end{array}$ & $\begin{array}{c}\text { Mortality ratio, left } \\
\text { versus right ( } 95 \% \mathrm{Cl})\end{array}$ & $\begin{array}{l}\text { No of } \\
\text { deaths }\end{array}$ & $\begin{array}{c}\text { Mortality ratio, left } \\
\text { versus right }(95 \% \mathrm{CI})\end{array}$ \\
\hline Breast cancer (174) & $1.00(0.98$ to 1.03$)$ & 21196 & $1.00(0.97$ to 1.03$)$ & 2714 & 1.00 (0.93 to 1.08$)$ \\
\hline \multicolumn{6}{|l|}{ Cardiovascular diseases: } \\
\hline All $(390-459,785$, and 798$)$ & $1.04(1.00 \text { to } 1.09)^{*}$ & 5739 & $1.01(0.96$ to 1.07$)$ & 3426 & $1.10(1.03$ to 1.18$) \dagger$ \\
\hline Ischaemic heart disease (410-414) & 1.06 (1.00 to 1.12$) \ddagger$ & 3078 & $1.02(0.95$ to 1.10$)$ & 1613 & $1.13(1.03$ to 1.25$) \S$ \\
\hline Other cardiovascular diseases & $1.03(0.97$ to 1.09$)$ & 2661 & $1.00(0.93$ to 1.08$)$ & 1813 & 1.08 (0.98 to 1.18$)$ \\
\hline Remaining causes & 0.97 (0.93 to 1.02) & 4446 & 0.96 (0.90 to 1.01$)$ & 2602 & 1.00 (0.92 to 1.07$)$ \\
\hline
\end{tabular}

CD-9=International classification of diseases, ninth revision. 